\title{
EFFECT OF ACCLIMATISATION TO ALTITUDE ON LEARNING
}

\author{
M. Pagani ${ }^{1}$, G. Ravagnan $^{1}$ and D. Salmaso ${ }^{2}$ \\ ( ${ }^{1}$ Institute of Experimental Medicine and ${ }^{2}$ Institute of Psychology of the National Research \\ Council (CNR), Rome, Italy)
}

\begin{abstract}
Long-term exposure to high altitude has been reported to impair cognitive functions, possibly resulting in an increased risk of mountain accidents. To assess the modification of cognitive functions during acclimatisation to altitude, 17 climbers were studied at $5350 \mathrm{~m}$ a.s.l. by means of a neuropsychological learning test. The results clearly show that by extending the period spent at elevations above $5350 \mathrm{~m}$ to more than 15 days, the response to a memory task was significantly enhanced. The improvements resulting from acclimatisation were more evident in the organisation of information than in information storage. We suggest that inappropriate acclimatisation has a detrimental effect on cognitive functions and the resulting impairment may particularly affect the more demanding technical tasks.
\end{abstract}

Key words: acclimatisation, memory disorders

\section{INTRODUCTION}

Almost 300 people die every year mountaineering in the Alpine Arch and in the Himalaya, up to 1993, one out of every four climbers that would reach the top of a peak higher than 8000 meters would die.

There is strong evidence that central nervous system (CNS) functions are impaired by long and repeated exposure to altitude and hypoxia (West, 1986; Lieberman, Protopapas, Reed et al., 1994). Whether these changes are transient or permanent is still to be determined (West, 1986; Townes, Hornbein, Schoene et al., 1984; Regard, Oelz, Brugger et al., 1989; Kramer, Coyne and Strayer, 1993). Cognitive deficits during hypoxia have been reported to be matched with improved physical performance (Herr, 1990; Hornbein, Townes, Schoene et al., 1989), but such decline in neurobehavioural performance may prompt irrational decisions leading to falls, accidents, exhaustion and death. Histologic animal studies have revealed that cortical layers III, V and VI and the hippocampus, striatum, thalamus and amygdala are the cerebral areas most vulnerable to hypoxic damage (Brierley, 1976).

Previous studies on the effects produced by hypoxia on cognitive functions suggest that in general they deteriorate. However the experimental conditions are widely heterogeneous across studies. Some of these investigations (Kramer et al., 1993; Regard, Landis, Casey et al., 1991; Sartori, Michielin and Prior, 1994: Lieberman et al., 1994) have shown a decrement of cognitive functions during experiments carried out in the field at high altitudes. Other studies have 
described a similar decrease in experiments performed at sea level before and after exposure to various altitudes (Townes, Hornbein, Schoene et al., 1984; Regard et al., 1989; Hornbein et al., 1989; Cavalletti and Tredici, 1993). Furthermore Crowley, Wesensten, Kamimori et al. (1992) have shown a decrement in cognitive functions under hypobaric hypoxia simulated in a decompression chamber, and Fowler, Prlic and Brabant (1994) found the same decrease in an experiment using a mixture of air and $10 \%$ oxygen. In contrast to these findings, experiments in a decompression chamber, where altitudes up to $5500 \mathrm{~m}$ were simulated (Kennedy, Dunlap, Banderet et al., 1989) and other experiments on Mount Everest at $6600 \mathrm{~m}$ (Nelson, Dunlosky, White et al., 1990), were unable to show any significant changes.

Although a previous study (Crowleys et al., 1992) has investigated the effects that prolonged exposure to simulated altitudes has on cognitive functions, to our knowledge no data are available on the effects that acclimatisation induces in memory in a natural environment, nor has anybody studied the possible differential effects of acclimatisation on different brain functions and areas.

Information storage and organization were investigated separately to gain a better understanding of hypoxia-induced cognitive changes by means of a newly developed analysis which takes into account both the quantitative and qualitative aspects of cognitive performance.

Two different experimental conditions were designed and separately analysed. In the between condition two different groups were considered, while in the within condition the same subjects were retested in order to control interindividual variability.

\section{EXPERIMENT 1 - BETWEEN CONDITION}

\section{Participants}

Seventeen trekkers and climbers belonging to four different national expeditions (4 women, 13 men, mean age 38.5, sd ó.2) were tested at the Base Camp of Kangchenjunga, Nepal (altitude $5350 \mathrm{~m}$ a.s.l.) during the autumn of 1995. All individuals reached the Base Camp after trekking for a period of between 10 and 13 days. After having reached an altitude of $3500 \mathrm{~m}$, the climbers got to the Base Camp in five days, ascending about 400 $\mathrm{m} /$ day. The test was administered in confortable tents and the subjects did not use supplementary oxygen. At the time of testing, none of them complained of symptoms (headache, nausea, vomit, difficulty in sleeping) nor did they show signs (alterations of mental status, ataxia, peripheral oedema) of acute mountain sickness (Hackett and Oelz, 1992) neither during the trekking nor during their stay at the Base Camp. They were free from symptoms of cold, fear, fatigue, hunger, thirst and sleep deprivation. The test was administered to nine subjects before acclimatisation (less than 3 days of exposure to an altitude of $5350 \mathrm{~m}$, non-acclimatised subjects) and to eight additional individuals after acclimatisation (between 15 and 20 days of exposure to an altitude of $5350 \mathrm{~m}$, acclimatised subjects). During the days before the test, this latter group was exposed to altitudes of up to $7300 \mathrm{~m}$. The mean age of the two groups was the same.

Owing to failure of the technical equipment, the instrumental data of the physiological parameters are not available, apart from the subjective and objective clinical evaluation of the absence of the symptoms of mountain sickness. 


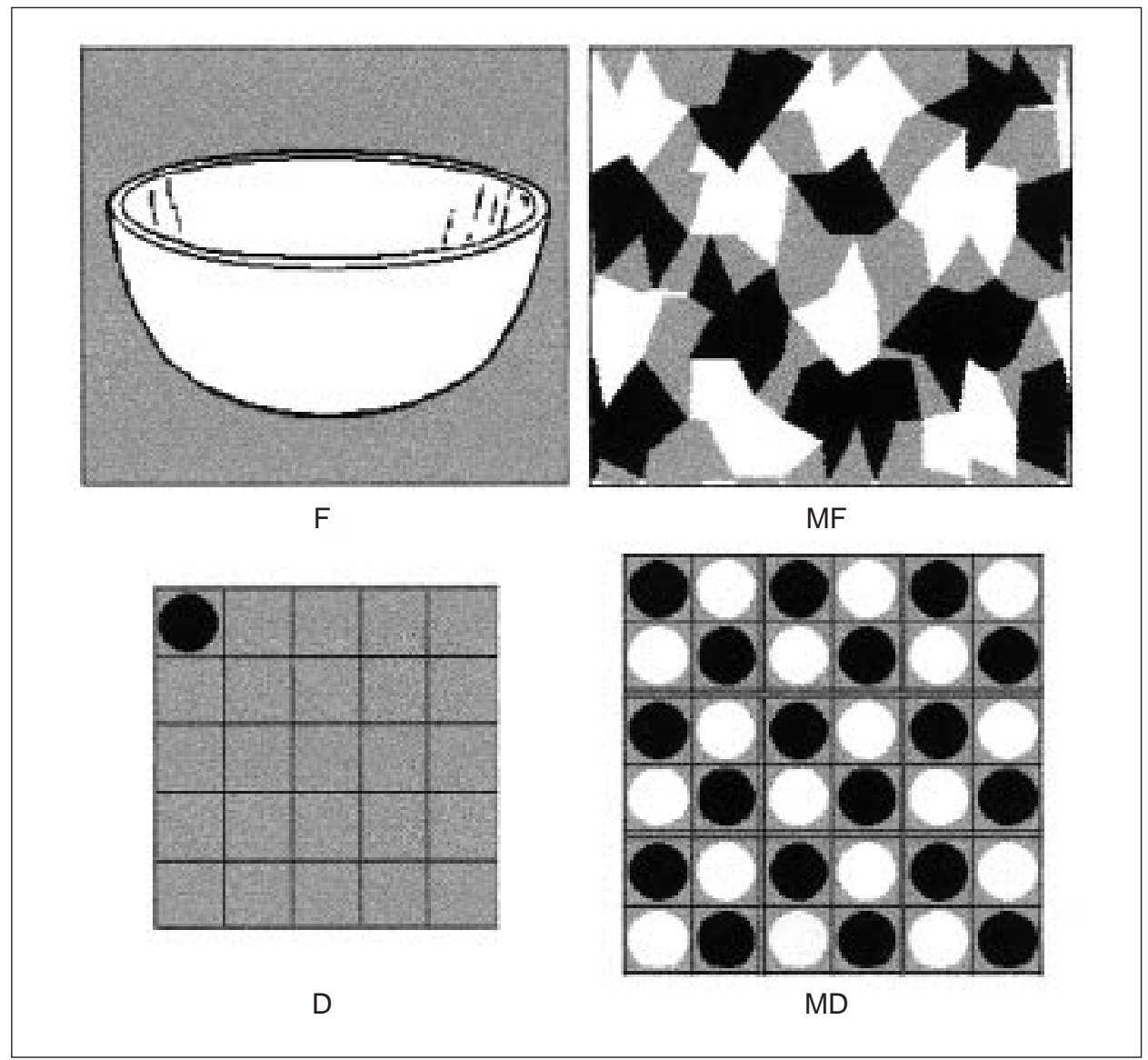

Fig. 1 - Examples of the stimuli used in the four tests: $(F)$ figure, $(M F)$ masking for figures, $(D)$ draughts, (MD) masking for draughts.

\section{Test}

The climbers were administered a learning test consisting of a series of 7 elements presented one after the other, to be learnt in the order of presentation.

Two different types of test were built, one with very familiar but unrelated figures (Familiarity - mean $=4.04$; from Snodgrass and Vanderwart, 1980), and the other consisting of black draughts randomly positioned on a $5 \times 5$ grey grid (modified from Rey, 1968). The 2 tests selected were meant to explore both verbal and spatial functions in the different experimental conditions.

Each test was presented in normal and masked conditions. In the case of the figures, the masking consisted of a patchwork of small black and white irregular polygons, whereas for the grid test, the masking consisted of a second $6 \times 6$ grey grid filled with black and white draughts. The masking preceded and followed each of the elements presented. In summary, four tests were administered: normal figures, masked figures, normal grid and masked grid (see Figure 1).

The tests were presented via a portable computer screen (TFT, Toshiba 4850) and each element of the test was clearly visible. The frequency of presentation was 1.2 elements/sec and each element was displayed for $70 \mathrm{msec}$. Subjects were given $30 \mathrm{sec}$ for repeating each 
series of elements in the order of presentation. Each series was re-administered in the same order, up to a maximum of 12 repetitions.

For the figure test, upon each repetition, the investigator would write down the objects in the order in which they were verbally recalled. Intrusions and duplications were also taken down. The test was performed in the native language of each participant.

For the grid test the individuals were asked to draw the draughts they had seen on an empty grid, and the investigator would track the order in which they were being drawn. Mistakes in positioning the draughts were considered intrusions. The boxes of the grid had not been numbered.

The total time for administering the four tests was at the most $30 \mathrm{~min}$. The order of presentation of the four tests would vary according to the Latin square design.

Cognitive performance was evaluated by means of two different kinds of analyses. The first took into account the number of repetitions needed to learn the correct sequence with a score of 12 being given to those who did not learn the series. The second analysis was based on two separate indices: index A referring to the number of correct elements recalled per repetition independently of their order, and index ITR (see Sternberg and Tulving, 1977) based on the sum of pairs of correct elements present in two sequential repetitions. The former can be considered as a simple storage index, since the correct sequence of elements is not taken into account. The latter reflects the observation that when a list is presented several times in the same order, items that are presented together are also recalled together. This phenomenon, known as seriation, can be assumed to be a primary indicator of memory organisation. With this second type of analysis the processes of information storage and organisation are studied together, and comparisons can be made between the two. A and ITR were calculated independently for each repetition, added up per test and divided by the highest value obtainable. The range of the indices varies between 0 and 1 , where 1 indicates the best performance, i.e. immediate learning.

\section{RESULTS}

The results obtained were analysed by analysis of variance (ANOVA) considering three factors, namely materials (figures and grids), masking (masked and non-masked), and the two experimental groups (acclimatised and nonacclimatised subjects).

In the first type of analysis, the number of repetitions needed to learn the sequence was analysed. The maximum value is 12 . The number of repetitions is greater in the non-acclimatised subjects as compared to the acclimatised ones [F $(1,15)=10.6, p=.005]$. Furthermore, the masking-acclimatisation interaction $[\mathrm{F}(1,15)=5.9, \mathrm{p}=.028]$ indicates that masking has a negative influence mainly on the performance of non-acclimatised subjects (see Table I).

Even in the second type of analysis, the ANOVA test showed a significant difference in learning after acclimatisation $[\mathrm{F}(1,15)=9.3, \mathrm{p}=.008]$. Masking conditions negatively affected performance $[\mathrm{F}(1,15)=20.6, \mathrm{p}=.000]$ and index A showed significantly higher mean values when compared to index ITR [F (1, $15)=190.9, \mathrm{p}<.000]$. Furthermore, as indicated by the indices-acclimatisation interaction $[\mathrm{F}(1,15)=5.5, \mathrm{p}=.033]$, index A was less affected by acclimatisation to altitude than ITR (see Figure 2). Also with masking, as shown by the maskingacclimatisation interaction $[\mathrm{F}(1,15)=8.0, \mathrm{p}=.013]$, the non-acclimatised subjects were those who were most negatively affected (see Figure 3). 


\section{EXPERIMENT 2 - WITHIN CONDITION}

\section{Participants}

The test was then readministered to seven of the nine non-acclimatised subjects between 15 and 18 days after the first administration. During this period, all subjects were exposed to altitudes of up to $7300 \mathrm{~m}$.

\section{Test}

Following acclimatisation, the subjects were exposed to the tests as in experiment 1 , but the series presented differed from those used in the first administration.

\section{RESULTS} ways.

Also for this second experiment the results were analysed in two different

With the first type of analysis, the number of repetitions (see Table I) was greater in the non-acclimatised state $[F(1,6)=36.4, p=.001]$. This difference is even more striking for the masked tasks when compared to the non-masked tasks as shown by the masking-acclimatisation interaction $[\mathrm{F}(1,6)=12.5, \mathrm{p}=.012]$.

With the second type of analysis the ANOVA test showed that learning was significantly easier after acclimatisation $[\mathrm{F}(1,6)=39.6, \mathrm{p}=.001]$ and $\mathrm{A}$ and ITR differed significantly $[\mathrm{F}(1,6)=183.8, \mathrm{p}<.000]$. However index A (see Figure 2) was less affected by acclimatisation to altitude than ITR [indicesacclimatisation interaction: $F(1,6)=15.2, p=.008]$ and the masking (see Figure 3) affected mainly the performance before acclimatisation [maskingacclimatisation interaction: $\mathrm{F}(1,6)=13.9, \mathrm{p}=.010]$.

\section{DISCUSSION}

The findings of the present study support the conclusion that cognitive performance improves considerably after acclimatisation. This effect is consistent, because it is found both in the "between" and in the "within" experiments. The poorer performance before acclimatisation can be attributed neither to fatigue, since all individuals were tested a few days after their arrival at the Base Camp, nor to mountain sickness, since none of the subjects suffered from such symptoms

TABLE I

Mean Number of Repetitions Needed to Learn Masked and Non-masked Tasks

\begin{tabular}{lcc}
\hline & Masked & Non-masked \\
\hline Between condition & & \\
$\quad$ Non-acclimatised & 7.65 & 4.05 \\
Acclimatised & 3.70 & 3.05 \\
Within condition & & \\
Before acclimatisation & 7.00 & 4.00 \\
After acclimatisation & 3.00 & 3.40 \\
\hline
\end{tabular}




\section{ALTITUDE ACCLIMATISATION \\ BETWEEN \& WITHIN EXPERIMENTS}

EXPERIMENTS \& MEASURES

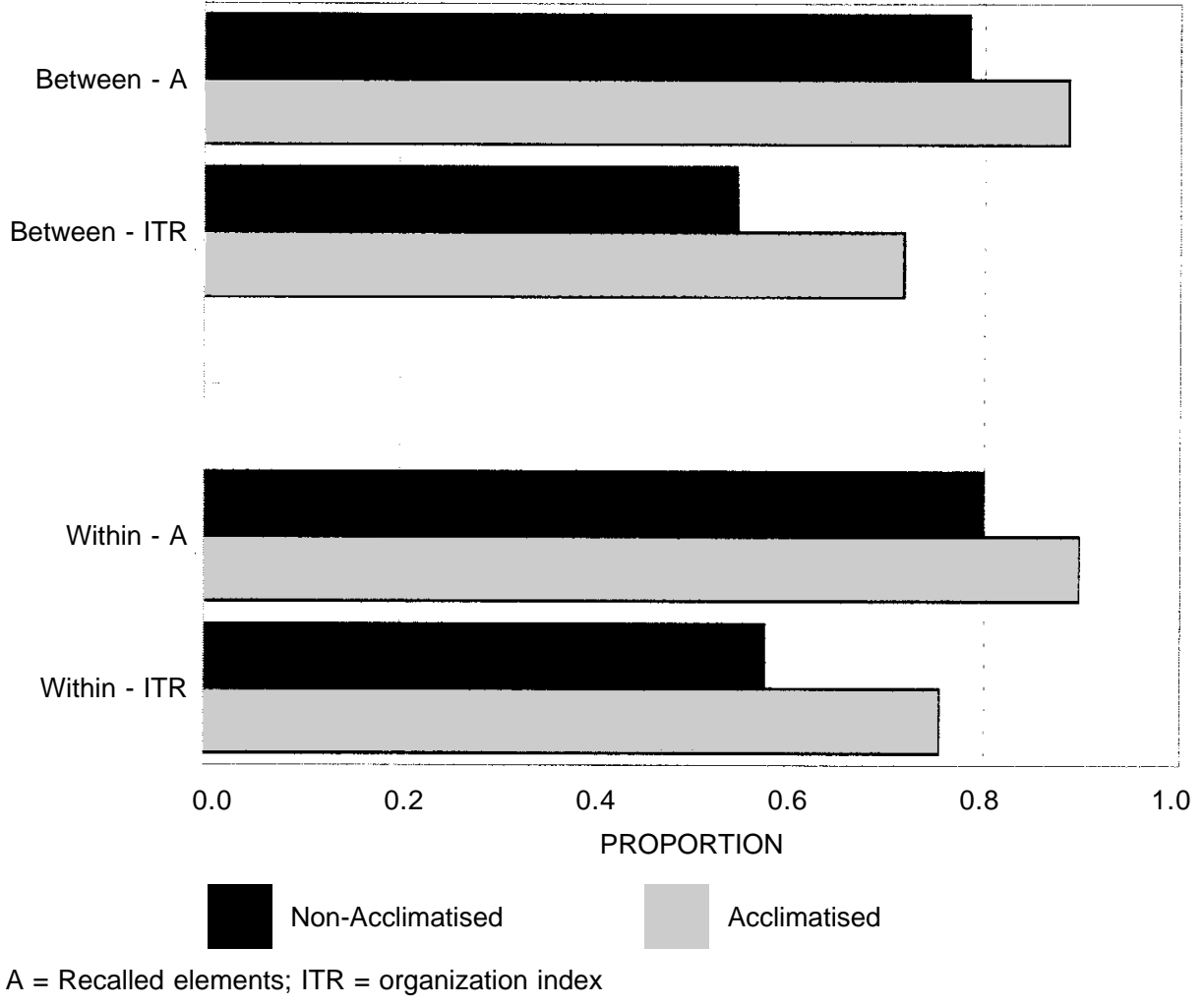

Fig. 2 - Values of A (recalled elements) and ITR (organisation index) relative to the between and within conditions. In the between condition 9 non-acclimatised and 8 acclimatised individuals were studied. In the within condition 7 climbers were studied before and after acclimatisation.

throughout the whole expedition. A retest effect could at most be entertained to account for the "within" group effect, not the "between group" effect.

Our results are in agreement with those obtained by Crowley et al. (1992) who described an initial decline followed by a progressive improvement in cognitive performance during prolonged exposure to acute hypobaric hypoxia in a decompression chamber.

The experimental design, which includes both the between and the within groups, makes the matching between the performances of these subjects and those of a control group irrelevant to the study. Furthermore, the uniqueness of the experimental conditions at the Base Camp and the special characteristics of the subjects studied render any comparison between the climbers and control groups at sea level inappropriate. On the other hand, it has not been possible to repeat the studies in normoxic condition on the same subjects. 


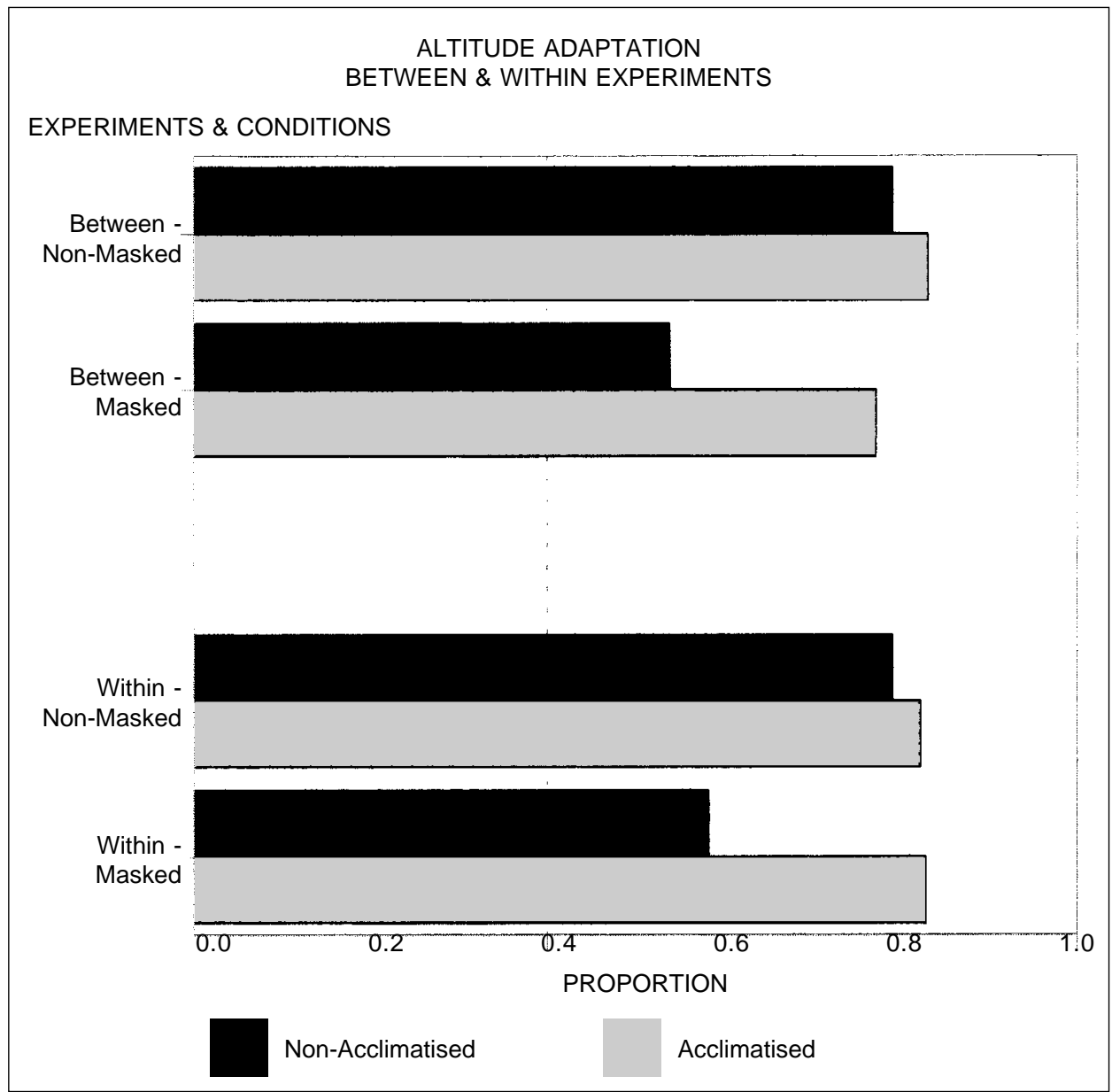

Fig. 3 - Averaged A and ITR values of masked and non-masked tests relative to the between and within conditions.

Hence our study suggests that the decreased learning ability is only attributable to the effects of hypobaric hypoxia on the brain and in particular on some of its structures.

While the role played by the hippocampus and the other limbic structures in memory is well known, recent studies (Shimamura, Janowsky and Squire, 1990; Squire, Knowlton and Musen, 1993; Tulving, Kapur, Craik et al., 1994) have stressed the role of prefrontal areas, as part of a more extensive network, involved in encoding and retrieval. In particular, the prefrontal lobes seem to play a critical role in the storage of temporal information which is required to place any event into its context (Schacter, 1987; Squire, 1987; McAndrews and Milner, 1991). In order for the subjects of the present study to be able to learn the series of elements in the right order, the time tags linked to each element needed to be processed.

Our results show that these time tags which were most affected by hypoxia and benefitted most from acclimatisation to altitude. The fact that the ITR index 
and the masking condition were specifically impaired by hypoxia suggests that the prefrontal cortex, in which the organisation of information is supposed to be processed, was more sensitive to altitude than the other cerebral structures involved in information storage. This is in agreement with the hypothesis that the prefrontal areas are among the ones most sensitive to acute cerebral hypoxia (Lieberman et al., 1994; Brierley, 1976).

This differential memory performance may be due to a marked decrease, during hypoxia, in the neuronal activity of the dopaminergic and cholinergic pathways connecting the basal ganglia to the prefrontal lobe (Kopf and Baratti, 1994; Shukitt-Hale, Stillman and Welch, 1994).

Acclimatisation to altitude is known to improve cardiocirculatory and ventilatory parameters affected by acute hypobaric hypoxia (Reeves, Groves, Sutton et al., 1987; West, 1989). Hypoxia results also in increased protein breakdown, decreased protein synthesis and rise in systemic blood pressure related to adrenergic activation (Rennie, Babij, Sutton et al., 1983; Cunningham, Becker and Kreuzer, 1965). One can also speculate that, since encoding and retrieval are very likely more oxygen- and energy-consuming than simple information storage, some central mechanism may control and modulate these functions so as to prevent the hypoxic failure of more vital systems. Furthermore neurotransmitters, receptors and new synaptic syntheses require constant protein uptake to carry out the memorisation process in which they are all involved (Agranoff, 1976). Altitude-related protein deficits may affect this mechanism.

In conclusion, this study has shown that acclimatisation results in better cognitive performance and that the type of analysis carried out was able to differentiate between two important aspects of memory. Climbing, like other complex tasks, requires time-based structuring and depends not only on physical effort but also on attention and technical skills, so it can be significantly affected by the lack of acclimatisation. Such conditions enhance the risk of mountain accidents and hence the suggestion that appropriate acclimatisation to altitude is mandatory.

Acknowledgements. This report is in memory of Benoit Chamoux, Pierre Royer and Riku Sherpa who died on the Kangchenjunga in October 1995. The study has been supported by "Progetto Strategico Everest-K2 CNR".

\section{REFERENCES}

AgRANOFF, B.W. Learning and memory: Approaches to correlating behavioral and biochemical events. In G.J. Siegel, R.W. Albergs, R. Katzman and B.W. Agranoff (Eds.), Basic Neurochemistry, 2nd ed. Boston: Little Brown, 1976.

Brierley, J.B. Cerebral hypoxia. In W. Blackwood and J.A.N. Corsellis (Eds.), Greenfield's Neuropathology. Chicago: Ybk Medicine, 1976.

Crowley, J.S., Wesensten, N., Kamimori, G., Devine, J., Iwanyk, E., and Balkin, T. Effect of high terrestrial altitude and supplemental oxygen on human performance and mood. Aviation, Space and Environmental Medicine, 63: 696-701, 1992.

Cavaletti, G., and Tredici, G. Long-lasting neuropsychological changes after a single high altitude climb. Acta Neurologica Scandinavica, 87: 103-105, 1993.

CunNingham, W.L., BeCKer, E.J., and KREUZER, F. Catecholamines in plasma and urine at high altitude. Journal of Applied Physiology, 20: 607-610, 1965.

Fowler, B., PrLIC, H., and Brabant, M. Acute hypoxia fails to influence two aspects of short-term memory: Implications for the source of cognitive deficits. Aviation, Space and Environmental Medicine, 65: 641-645, 1994.

Hackett, P.H., and Oelz, O. The lake Louise consensus on the definition and quantification of altitude 
illness. In J.R. Sutton, G. Coates and C.S. Houston (Eds.), Hypoxia and Mountain Medicine. Burlington: Queen City Printers, 1992.

HERR, R.D. High altitude and the central nervous system. New England Journal of Medicine, 322: 1821, 1990.

Hornbein, T.F., Townes, B.D., Schoene, R.B., Sutton, J.R., and Houston, C.S. The cost to the central nervous system of climbing to extremely high altitude. New England Journal of Medicine, 321 : 1714-1719, 1989.

Kennedy, R.S., Dunlap, W.P., Banderet, L.E., Smith, M.G., and Houston, C.S. Cognitive performance deficits in a simulated climb of Mount Everest: Operation Everest II. Aviation, Space and Environmental Medicine, 60: 99-104, 1989.

Kopf, S.R., and BARATTI, C.M. Memory-improving actions of glucose: Involvement of a central cholinergic muscarinic mechanism. Behavioral and Neural Bioloqy, 62: 237-243, 1994.

Kramer, A.F., Coyne, J.T., and Strayer, D.L. Cognitive function at high altitude. Human Factors, 35 : 329-344, 1993.

Lieberman, P., Protopapas, A., Reed, E., Youngs, W., and Kanki, B.G. Cognitive defects at altitude. Nature, 372: 325, 1994.

McAndrews, M.P., and Milner, B. The frontal cortex and memory for temporal order. Neuropsychologia, 29: 849-859, 1991.

Nelson, T.O., Dunlosky, J., White, D.M., Steinberg, J., Townes, B.D., and Anderson, D. Cognition and metacognition at extreme altitudes on Mount Everest. Journal of Experimental Psychology, General, 119: 367-374, 1990.

Reeves, J.T., Groves, B.M., Sutton, J.R., Wagner, P.D., Cymerman, A., Malconian, M.K., Rock, P.D., YounG, P.M., and Houston, C.S. Operation Everest II: preservation of cardiac function at extreme altitude. Journal of Applied Physiology, 63: 531-539, 1987.

Regard, M., Oelz, O., Brugger, P., and Landis, T. Persistent cognitive impairment in climbers after repeated exposure to extreme altitude. Neurology, 39: 210-213, 1989.

Regard, M., Landis, T., Casey, J., Maggiorini, M., Bartsch, P., and Oelz, O. Cognitive changes at high altitude in healthy climbers and in climbers developing acute mountain sickness. Aviation, Space and Environmental Medicine, 62: 291-295, 1991.

Rennie, M.J ., Babis, P., Sutton, J.R., Tonkins, W.J., Read, W.W., Ford, C., and Halliday, D. Effects of acute hypoxia on forearm leucine metabolism. In J.R. Sutton, C.S. Houston and N.L. Jones (Eds.), Hypoxia, Exercise and Altitude. New York: Liss, 1983.

REY, A. Epreuves Mnesiques et d'Apprentissage: Fascicule III. Neuchatel: Delachaux and Niestlè, Suisse, 1968.

SARtori, G., Michielin, P., and Prior, M. Modificazioni delle funzioni cognitive in alta quota. Risultati del progetto EV-K2-CNR "Human Factors”. Giornale Italiano di Psicologia, XXI: 577-590, 1994.

SCHACTER, D.L. Memory, amnesia and frontal lobes dysfunction. Psychobiology, 15: 21-36, 1987.

Shimamura, A.P., JANOWSKY, J.S., and SQUiRE, L.R. Memory for the temporal order of events in patients with frontal lobe lesions and amnesic patients. Neuropsychologia, 28: 803-813, 1990.

Shukitt-Hale, B., Stillman, M.J., Welch, D.I., Levy, A., Devine, J.A., and Lieberman, H.R. Hypobaric hypoxia impairs spatial memory in an elevation-dependent fashion. Behavioral and Neural Biology, 62: 244-252, 1994.

SNODGRASS, J.G., and VANDERWART, M. A Standardized set of 260 pictures; norms for name agreement, image agreement, familiarity, and visual complexity. Journal of Experimental Psychology, Human Learning and Memory, 6: 174-215, 1980.

SQUIRE, L.R. Memory and Brain. New York: Oxford University Press, 1987.

SQuire, L.R., Knowlton, B., and Musen, G. The structure and organization of memory. Annual Review of Pyschology, 44: 453-495, 1993.

Sternberg, R.J., and Tulving, E. The measurement of subjective organization in free recall. Psychological Bullettin, 84: 539-566, 1977.

Townes, B.D., Hornbein, T.F., Schoene, R.M., Sarnquest, F.H., and Grant, I. Human cerebral function at extreme altitude. In J.B. West and S. Lahiri (Eds.), High Altitude and Man. Washington: American Physiological Society, 1984.

Tulving, E., Kapur, S., Craik, F.I.M., Moscovitch, M., and Houle, S. Hemispheric encoding/retrieval asymmetry in episodic memory: positron emission tomography findings. Proceedings of National Academy of Sciences of the USA, 91: 2016-2020, 1994.

WEST, J.B. Do climbs to extreme altitude cause brain damage? Lancet, II: 387-388, 1986.

West, J.B. The 1988 Stevenson Memorial Lecture. Physiological responses to severe hypoxia in man. Canadian Journal of Physiology and Pharmacology, 67: 173-178, 1989.

Dr. Dario Salmaso, CNR, Istituto di Psicologia, viale Marx, 15, 00137 Roma.

(Received 28 October 1996; accepted 25 July 1997) 